\title{
Cancer-associated oxidoreductase ERO1- $\alpha$ drives the production of VEGF via oxidative protein folding and regulating the mRNA level
}

Tsutomu Tanaka*,1,2, Goro Kutomi ${ }^{3}$, Toshimitsu Kajiwara ${ }^{1}$, Kazuharu Kukita ${ }^{3}$, Vitaly Kochin ${ }^{1}$, Takayuki Kanaseki ${ }^{1}$, Tomohide Tsukahara ${ }^{1}$, Yoshihiko Hirohashi ${ }^{1}$, Toshihiko Torigoe ${ }^{1}$, Yoshiharu Okamoto ${ }^{4}$, Koichi Hirata ${ }^{3}$, Noriyuki Sato ${ }^{1}$ and Yasuaki Tamura ${ }^{5}$

${ }^{1}$ Department of Pathology, Sapporo Medical University, S1W17, Chuo-ku, Sapporo 060-8556, Japan; ${ }^{2}$ The United Graduate School of Veterinary Sciences, Yamaguchi University, 1677-1, Yoshida, Yamaguchi 753-8511, Japan; ${ }^{3}$ Department of Surgery, Sapporo

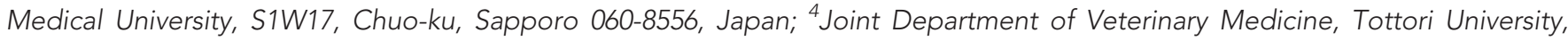
4-101, Koyama-cho Minami 680-8550, Tottori, Japan and ${ }^{5}$ Center for Innovation and Business Promotion, Hokkaido University, N21W11, Kita-ku, Sapporo 001-0021, Japan

Background: Endoplasmic reticulum disulfide oxidase 1- $\alpha(E R O 1-\alpha)$ is an oxidase that exists in the endoplasmic reticulum and has a role in the formation of disulfide bonds of secreted proteins and cell-surface proteins. Recently, we reported that ERO1- $\alpha$ is present in high levels in various types of tumours, and that ERO1- $\alpha$ is a novel factor of poor prognosis. However, how ERO1- $\alpha$ affects a tumour in vivo and why patients who have a tumour with a high expression level of ERO1- $\alpha$ have a poor prognosis are still unknown. Therefore, to clarify the mechanism, we investigated the effect of ERO1- $\alpha$ on a tumour from the point of view of angiogenesis.

Methods: The effect of ERO1- $\alpha$ on tumour growth and angiogenesis was analysed by using non-obese diabetic-severe combined immunodeficient mice. The production of vascular endothelial growth factor (VEGF) in MDA-MB-231 cells with ERO1- $\alpha$ overexpression or with ERO1- $\alpha$ knockdown was measured. The role of ERO1- $\alpha$ on VEGF expression was investigated. In triplenegative breast cancer cases, the relationship between expression of ERO1- $\alpha$ and angiogenesis was analysed.

Results: We found that the expression of ERO1- $\alpha$ promoted tumour growth in a mouse study and angiogenesis. The effects of ERO1- $\alpha$ on angiogenesis were mediated via oxidative protein folding of VEGF and enhancement of VEGF mRNA expression by using MDA-MB-231. In triple-negative breast cancer cases, the expression of ERO1- $\alpha$ related to the number of the blood vessel. Furthermore, we found that ERO1- $\alpha$ was a poor prognosis factor in triple-negative breast cancer.

Conclusions: Our study has established a novel link between expression of ERO1- $\alpha$ and secretion of VEGF, providing new evidence for the effectiveness of ERO1- $\alpha$-targeted therapy in patients with ERO1- $\alpha$-expressed cancer.

Breast cancer has been the most common cancer worldwide in women in the past decade (Curado, 2011). Many molecular target drugs against breast cancer have been examined in the recent years.
The development of new drugs has resulted in longer overall survival for patients with human epidermal growth factor receptor type2 (HER2) type and luminal type of breast cancer. However,

*Correspondence: Dr T Tanaka; E-mail: t_tanaka0925@yahoo.co.jp

Received 9 August 2015; revised 1 March 2016; accepted 11 March 2016; published online 21 April 2016

(c) 2016 Cancer Research UK. All rights reserved 0007-0920/16 
triple-negative breast cancer (TNBC) does not have a cell-surface protein, such as HER2, oestrogen receptor and progesterone receptor, that can be used as a target for a molecular target drug. Moreover, TNBC is generally characterised as having a high rate of distant metastasis and poor disease-specific survival compared with other breast cancer subtypes (Mittendorf et al, 2014).

Angiogenesis is one of the important hallmarks of cancer (Xu et al, 2015), and it is vital for tumourigenesis and tumour development because tumours cannot grow $>2 \mathrm{~mm}$ in diameter without angiogenesis (Zhang et al, 2015) It is well-known that vascular endothelial growth factor (VEGF), which functions by binding to both VEGF receptors 1 and 2, is the master regulator of angiogenesis (Xu et al, 2015). Recent studies have demonstrated that X-linked inhibitor of apoptosis-associated factor 1 (Zhu et al, 2014) and several miRNAs (Hua et al, 2006; Lee et al, 2007; Kuehbacher et al, 2008; Wang and Olson, 2009; Hong et al, 2013; Zhang et al, 2015) are associated with angiogenesis. It had also been shown that patients treated with bevacizumab, an antibody against VEGF, had longer overall survival than that of patients not treated with bevacizumab (Redondo et al, 2014). Thus, a strategy for decreasing the amount of VEGF secretion from a tumour is promising for treatment of breast cancer.

Endoplasmic reticulum disulfide oxidase $1-\alpha($ ERO1- $\alpha)$ is an oxidase located in the endoplasmic reticulum. Recently, we have shown that ERO1- $\alpha$ is present in high levels in various types of tumours, and that ERO1- $\alpha$ is a poor prognosis factor of breast cancer (Kutomi et al, 2013). However, how ERO1- $\alpha$ affects tumour growth in vivo and why patients who have a tumour with a high expression level of ERO1- $\alpha$ have a poor prognosis are still unknown.

In this study, we found that expression of ERO1- $\alpha$ was the poor prognosis factor in TNBC and that the expression of ERO1- $\alpha$ correlated with the secretion of VEGF and angiogenesis in in vivo tumour models and clinical cases. The results of our study suggest that ERO1- $\alpha$-targeted therapy such as knockdown of ERO1- $\alpha$ or blockade of ERO1- $\alpha$ function will be an effective strategy for cancer.

\section{MATERIALS AND METHODS}

Cells and agents. The human breast cancer lines MDA-MB-157, MDA-MB-231, MDA-MB-468 and MCF7, the human pancreas cancer cell line MIAPaCa2 and the human gastric cancer cell line MKN45 were purchased from ATCC (Manassas, VA, USA). MDA-MB-157 cells were cultured in Roswell Park Memorial Institute-1640 (Sigma-Aldrich, St Louis, MO, USA) and MDAMB-231, MDA-MB-468, MCF7, MIAPaCa2 and MKN45 cells were cultured in Dulbecco's modified Eagle's medium (DMEM; Sigma-Aldrich) supplemented with $10 \%$ fetal calf serum (FCS) at $37^{\circ} \mathrm{C}$ in $5 \% \quad \mathrm{CO}_{2}$. Short-hairpin RNA for human ERO1- $\alpha$ (TR313168) was purchased from OriGene (Rockville, MD, USA) and transfected to MDA-MB-231, MCF7 and MIAPaCa2 cells using Lipofectamine 2000 (Life Technologies, Carlsbad, CA, USA). To establish cells with ERO1- $\alpha$-overexpression, MDA-MB-231 cells were transfected with human ERO1- $\alpha$ cDNA using Lipofectamine 2000 (Life Technologies) as per the manufacturer's instructions. Cells were stably propagated under puromycin selection ( 1 or $2 \mu \mathrm{g} \mathrm{ml}^{-1}$ ). The ERO1- $\alpha$ inhibitor EN460 was purchased from Millipore (Billerica, MA, USA).

In vivo study. Female non-obese diabetic-severe combined immunodeficient (NOD/SCID) mice, 4 weeks old, were obtained from Sankyo Laboratory Co. Ltd. (Tsukuba, Japan) and used at 5 weeks of age. Studies were performed with approval of the Animal Experiment Ethics Committee of Sapporo Medical University
(Sapporo, Japan). For tumour-formation studies, mice were injected with $1 \times 10^{6}$ MDA-MB-231 cells, ERO1- $\alpha$-overexpressed (OE) cells or ERO1- $\alpha$ knockdown (KD) cells into the right fourth mammary glands. Tumour growth was measured 2-3 times per week in two dimensions, and tumour volume was calculated using the formula $3.14 \times\left(\right.$ width $^{2} \times$ length $) / 6$. Tumour length and width were measured with a pair of calipers.

Real-time PCR analysis. Total RNA was isolated from cultured cells and normal breast tissues using Isogen reagent (Nippon Gene, Tokyo, Japan) and RNeasy Mini kits (QIAGEN, Valencia, CA, USA) according to the manufacturers' instructions. The cDNA mixture was synthesised from $1 \mu \mathrm{g}$ total RNA by reversetranscription using Superscript III and oligo (dT) primer (Life Technologies) according to the manufacturer's protocol. Realtime polymerase chain reaction (real-time PCR) was performed to determine the expression levels of ERO1- $\alpha$, VEGF and $\beta$-actin. Expression values for each sample were normalised to $\beta$-actin, and fold levels of the indicated genes represent the mean ( \pm s.e.m.) of replicate reactions. Primer sequences were as follows: $\beta$-actin (ACTB), Hs01060665_g1; ERO1- $\alpha$ (ERO1L), Hs00205880_m1; and VEGF, Hs00900055_m1 (Life Technologies). PCR cycles were performed on the StepOne Real-Time PCR System (Life Technologies) with the following cycle conditions: $2 \mathrm{~min}$ at $50^{\circ} \mathrm{C}, 10 \mathrm{~min}$ at $95^{\circ} \mathrm{C}, 45$ cycles of $15 \mathrm{~s}$ at $95^{\circ} \mathrm{C}$ and $1 \mathrm{~min}$ at $60^{\circ} \mathrm{C}$. The delta-delta $\mathrm{Ct}$ method was used for data analysis.

Western blot analysis. ERO1- $\alpha$ recombinant protein was purchased from Abnova (Taipei, Taiwan). BSA was purchased from Wako Pure Chemical Industries, Ltd. (Osaka, Japan). Normal breast tissue extract was purchased from Santa Cruz Biotechnology (Dallas, TX, USA). Cultured cells were washed in ice-cold phosphate-buffered saline (PBS), lysed by incubation on ice in a lysis buffer $\left(50 \mathrm{mmoll}^{-1}\right.$ Tris- $\mathrm{HCl}\left(\mathrm{pH} 7.5,150 \mathrm{mmoll}^{-1} \mathrm{NaCl}\right.$, $5 \mathrm{mmoll}^{-1}$ EDTA, 1\% NP40), and cleared by centrifugation at $21880 \mathrm{~g}$ for $30 \mathrm{~min}$ at $4{ }^{\circ} \mathrm{C}$. For blockade of free thiols, cells were pretreated for $5 \mathrm{~min}$ with $10 \mathrm{mM}$ methyl methanethiosulfonate (MMTS; Pierce, Rockford, IL, USA) in PBS. Post-nuclear supernatants were divided and heated for $5 \mathrm{~min}$ at $95^{\circ} \mathrm{C}$ in a nonreducing or reducing sodium dodecyl sulfate (SDS) sample buffer, resolved by SDS-PAGE and electrophoretically transferred to PVDF membranes (Immobilon-P; Millipore). The membranes were incubated with blocking buffer (5\% non-fat dried milk in PBS) for $30 \mathrm{~min}$ at room temperature and then incubated overnight with anti-ERO1- $\alpha$ mAb (Abnova), anti-HIF mAb (BD, San Jose, CA, USA), anti-VEGF polyclonal antibody (Santa Cruz Biotechnology), or mouse anti- $\beta$-actin mAb AC-15 (SigmaAldrich). After washing three times with wash buffer $(0.05 \%$ Tween-20 in Tris-buffered saline), the membranes were reacted with peroxidase-labelled goat anti-mouse IgG antibody or peroxidase-labelled goat anti-rabbit IgG antibody (KPL, Gaithersburg, MD, USA) for $3 \mathrm{~h}$. Finally, the signal was visualised using an ECL detection system (Amersham Life Science, Arlington Heights, IL, USA) according to the manufacturer's protocol.

Analysis of reactive oxygen species level. Cells were collected by trypsinization, washed with DMEM twice, resuspended in FCS-free DMEM with $10 \mu \mathrm{M}$ of 5-(and-6)-chloromethyl-2', $7^{\prime}$-dichlorofluorescine diacetate, acetyl ester (CM- $\mathrm{H}_{2} \mathrm{DCFDA}$; Life Technologies), and incubated at $37^{\circ} \mathrm{C}$ for $30 \mathrm{~min}$ in the dark. Then fluorescence intensity was determined by using a FACSCalibur flow cytometer (BD) and FlowJo (Tree Star Inc., Ashland, OR, USA).

Immunohistochemistry. Tissue was fixed in neutral $10 \%$ buffered formaldehyde, embedded in paraffin and cut into $5-\mu \mathrm{m}$-thick slices for ERO1- $\alpha$ staining and CD31 staining. Reactivity of the antiERO1- $\alpha$ mAb was determined by perinuclear staining within tumour cells, indicating endoplasmic reticulum localisation. 
Anti-CD31 polyclonal antibody, which was used for staining of blood vessels in tumour tissues obtained from mice, was purchased from Abcam (Cambridge, MA, USA).

Enzyme-linked immunosorbent assay. MDA-MB-231 cells were plated at $2 \times 10^{5}$ cells in a $10-\mathrm{cm}$ dish and were incubated for 4 days. In the study using the ERO1- $\alpha$ inhibitor EN460, MDA-MB231 cells were plated at $5 \times 10^{5}$ cells per well in 6-well plates and were incubated with $0-12.5 \mu \mathrm{M}$ EN460 for $24 \mathrm{~h}$. MCF7 and MIAPaCa2 cells were plated at $1 \times 10^{5}$ cells per well in 6-well plates and were incubated for $24 \mathrm{~h}$. SiRNA for human ERO1- $\alpha$ (SR309340) was purchased from OriGene and transfected to MDA-MB-157 and MKN45 cells using RNAiMAX (Life Technologies). After 3 days, MDA-MB-157 and MKN45 Cells were plated at $1 \times 10^{5}$ cells per well in 6-well plates and were incubated for $24 \mathrm{~h}$. All samples were stored at $-80^{\circ} \mathrm{C}$ until assayed. Human VEGF (R\&D Systems, Minneapolis, MN, USA) levels were measured using a sandwich enzyme-linked immunosorbent assay (ELISA) kit. Absorbance was determined at $450 \mathrm{~nm}$.

Patients. Tissue samples were obtained from 56 patients diagnosed with TNBC from 2004 to 2010 at Sapporo Medical University Hospital. A total of 56 specimens of primary invasive carcinoma were obtained from resected tumours. Other background data for the patients are shown in the Supplementary Table 1. The expression of aldehyde dehydrogenase-1 (ALDH1) and ERO1- $\alpha$ was determined immunohistochemically in paraffinembedded tissue specimens. A mAb against CD31 was purchased from Leica Biosystems (Nussloch, Germany), and a mAb against ALDH1 was purchased from BD. The expression status of ERO1- $\alpha$ was graded as described by Kutomi et al (2013): score 0 (positive cells $0 \%$ ), score 1 (positive cells $<10 \%$ ), score $2(10 \% \geqslant$ positive cells $\leqslant 30 \%$ ), score 3 (positive cells $>30 \%$ ). Total populations of score 1 were included as the ERO1- $\alpha$ reduced group and score 2 and score 3 were regarded as the ERO1- $\alpha$ positive group. The expression status of ALDH1 was graded by our original classification: score 0 (positive cells $0 \%$ ), score 1 (positive cells $<0.5 \%)$, score $2 \quad(0.5 \% \geqslant$ positive cells $\leqslant 2.0 \%)$, score 3 (positive cells $>2.0 \%$ ). Histological examinations were carried out on slides with paraffin-embedded samples stained by $\mathrm{H} \& \mathrm{E}$ according to the criteria of the Japanese Breast Cancer Society, which are based on the International Union against Cancer TMN classification criteria.

Statistical analysis. Student's $t$-test was used for the analysis of two unpaired samples. Statistical differences in results of the study in vivo were analysed by Student's $t$-test and Mann-Whitney's $U$-test. Overall survival rates were calculated by the Kaplan-Meier method, and differences in survival curves were assessed by the log-rank test. The Cox-proportional hazards model was used for multivariate analysis. Tukey's test was used for the analysis of the number of blood vessels in clinical case. All analyses were carried out with STATMATE version 3.19 (ATMS Co., Ltd., Tokyo, Japan) and SPSS version 18.0 (SPSS Inc., Chicago, IL, USA). A $P<0.05$ was regarded as statistically significant. All statistical tests were two-sided.

\section{RESULTS}

Expression of ERO1- $\alpha$ is a poor prognosis factor for TNBC. We have reported that the expression of ERO1- $\alpha$ within a tumour is a poor prognosis factor in breast carcinoma (Kutomi et al, 2013). To further examine the effect of ERO1- $\alpha$ on TNBC, we classified clinical cases $(n=56)$ into 4 groups based on the expression of ERO1- $\alpha$ (Figure 5A). In univariate survival analysis, patients with ERO1- $\alpha 2+$ or $3+$ had significantly shorter overall survival than

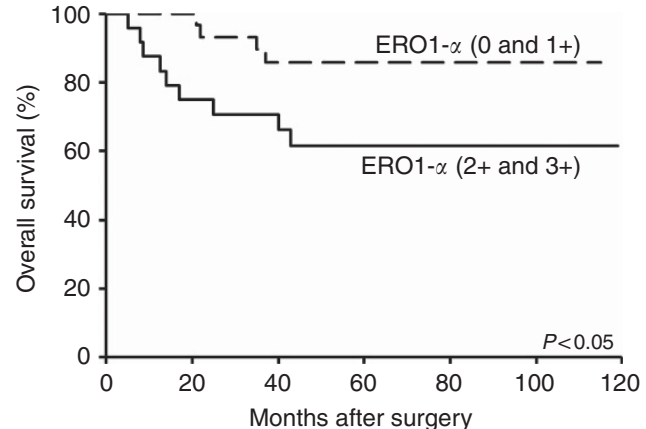

Figure 1. Kaplan-Meier analysis of overall survival for ERO1- $\alpha$ expression in 56 cases of invasive TNBC.

Table 1. Univariate and multivariate survival analyses in TNBC patients $(n=56)$

\begin{tabular}{|c|c|c|c|c|}
\hline Items & Contents & HR & $95 \% \mathrm{Cl}$ & $P$-value \\
\hline \multicolumn{5}{|c|}{ Univariate survival analysis } \\
\hline Age & $\begin{array}{l}<60 \text { years } \\
60-69 \text { years } \\
\geqslant 70 \text { years } \\
\text { Total }\end{array}$ & $\begin{array}{l}1 \\
2.17 \\
2.41\end{array}$ & $\begin{array}{l}0.61,7.70 \\
0.60,9.73\end{array}$ & $\begin{array}{l}0.23 \\
0.218 \\
0.157\end{array}$ \\
\hline Basal & $\begin{array}{l}\text { Non-basal } \\
\text { Basal } \\
\text { Total }\end{array}$ & $\begin{array}{l}1 \\
5.92\end{array}$ & $0.77,45.63$ & $\begin{array}{l}- \\
0.088 \\
-\end{array}$ \\
\hline Stage & $\begin{array}{l}\text { I or II } \\
\text { III } \\
\text { IV } \\
\text { Total }\end{array}$ & $\begin{array}{c}1 \\
3.66 \\
10.09\end{array}$ & $\begin{array}{l}0.94,14.17 \\
2.55,39.93\end{array}$ & $\begin{array}{r}- \\
0.061 \\
0.001 \\
<0.001\end{array}$ \\
\hline ALDH1 & $\begin{array}{l}(-) \\
(1+) \\
(2+) \\
(3+) \\
\text { Total }\end{array}$ & $\begin{array}{l}1 \\
2.02 \\
3.6 \\
2.08\end{array}$ & $\begin{array}{l}0.37,11.02 \\
0.51,25.64 \\
0.35,12.45\end{array}$ & $\begin{array}{l}- \\
0.418 \\
0.201 \\
0.423 \\
0.386\end{array}$ \\
\hline ERO1- $\alpha$ & $\begin{array}{l}(-) \text { or }(1+) \\
(2+) \\
(3+) \\
\text { Total }\end{array}$ & $\begin{array}{l}1 \\
4.95 \\
5.99\end{array}$ & $\begin{array}{l}0.91,27.06 \\
1.09,32.76\end{array}$ & $\begin{array}{l}- \\
0.065 \\
0.039 \\
0.029\end{array}$ \\
\hline \multicolumn{5}{|c|}{ Multivariate survival analysis } \\
\hline Stage & $\begin{array}{l}\text { I or II } \\
\text { III } \\
\text { IV } \\
\text { Total }\end{array}$ & $\begin{array}{c}1 \\
1.79 \\
14.92 \\
\end{array}$ & $\begin{array}{c}0.35,9.26 \\
2.20,101.09\end{array}$ & $\begin{array}{l}0.489 \\
0.006 \\
0.011\end{array}$ \\
\hline ERO1- $\alpha$ & $\begin{array}{l}(-) \text { or }(1+) \\
(2+) \\
(3+) \\
\text { Total }\end{array}$ & $\begin{array}{l}1 \\
6.69 \\
5.99\end{array}$ & $\begin{array}{l}1.01,44.15 \\
1.05,36.23\end{array}$ & $\begin{array}{l}- \\
0.048 \\
0.044 \\
0.041\end{array}$ \\
\hline
\end{tabular}

that of patients with ERO1- $\alpha 0$ or $1+$ (Figure 1 and Table 1$)$. In multivariate analysis of overall survival by Cox regression analysis, tumour stage and expression of ERO1- $\alpha$ were independent prognosis factors (Table 1).

Expression of ERO1- $\alpha$ in TNBC cell lines, TNBC tissues and normal breast tissues. We have reported that the expression of ERO1- $\alpha$ was enhanced in a variety of cancer cells (Kutomi et al, 2013). To determine the expression of ERO1- $\alpha$ in TNBC, we used antibodies specific to ERO1- $\alpha$. The specificity of ERO1- $\alpha$ antibody for immunohistochemistry was shown by Kukita et al (2015). In addition, we examined the specificity of ERO1- $\alpha$ antibody for Western blotting analysis by using ERO1- $\alpha$ recombinant protein 
A

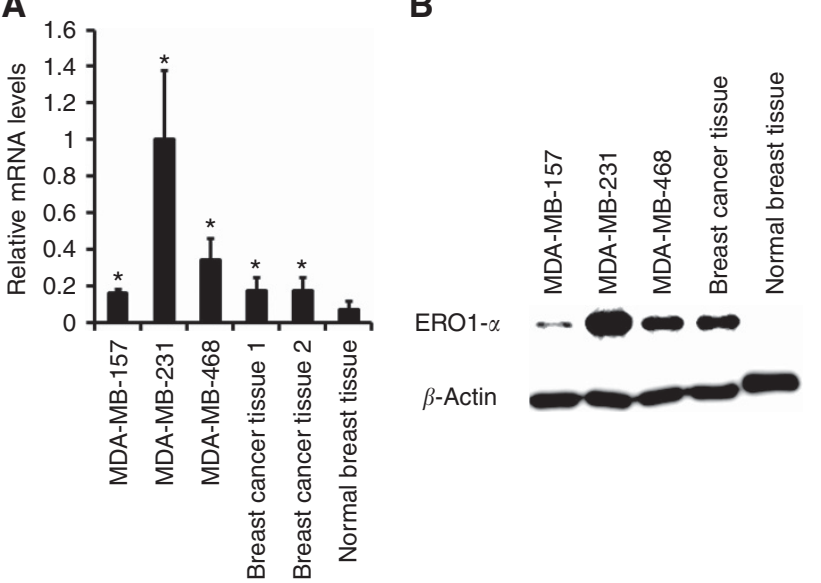

C

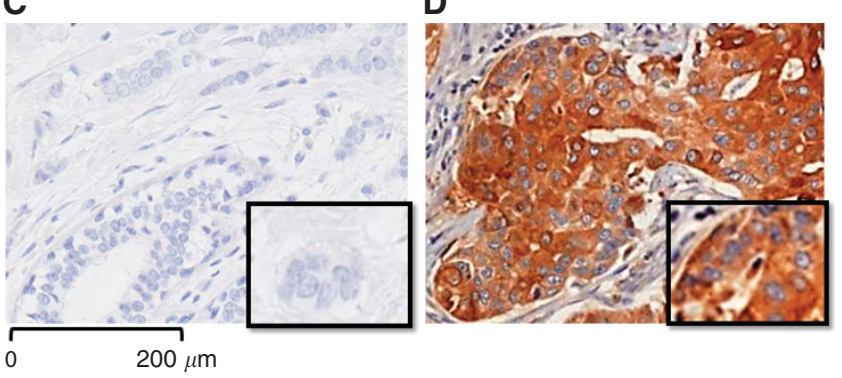

Figure 2. Expression of ERO1- $\alpha$ in TNBC tissue was enhanced compared with that in normal breast tissue. (A) Human ERO1- $\alpha$ mRNA levels in TNBC cell lines, TNBC tissues and normal breast tissue determined by real-time PCR. (B) Western blot analysis of TNBC cell lines, TNBC tissue and normal breast tissue. (C) Normal breast tissue and (D) TNBC tissue were stained for ERO1- $\alpha(\times 100$, inset: $\times 200)$. ${ }^{\star} P<0.05$, unpaired Student's $t$-test.

and BSA. As shown in Supplementary Figure 1, we confirmed that the mAb to ERO1- $\alpha$ specifically recognised the recombinant ERO1- $\alpha$ protein. These results indicated that the mAb to ERO1- $\alpha$ used in the present study was specific for ERO1- $\alpha$ protein.

In TNBC cell lines and TNBC tissues, the expression of ERO1- $\alpha$ was upregulated compared with the expression of ERO1- $\alpha$ in normal breast tissue at the mRNA (Figure 2A) and protein levels (Figure 2B). Immunohistochemical staining also showed that ERO1- $\alpha$ was overexpressed in tumour cells but not in normal breast tissue (Figure 2C and D).

Expression of ERO1- $\alpha$ in MDA-MB-231 cells promotes tumour growth via promoting angiogenesis. To examine the role of ERO1- $\alpha$ in tumour growth, we established ERO1- $\alpha$ knockdown TNBC MDA-MB-231 (sh221 and sh222) cells by using shRNA against ERO1- $\alpha$ (Figure 3A). When NOD/SCID mice were challenged with MDA-MB-231 cells transfected with scrambled shRNA (SCR cells) and KD cells, we observed that KD cells caused retardation of tumour growth, whereas wild-type and SCR cells did not (Figure 3B). We then investigated the mechanism by which knockdown of ERO1- $\alpha$ caused retardation of tumour growth. Immunohistochemistorical analysis showed that knockdown of ERO1- $\alpha$ decreased the number of $\mathrm{CD}_{3} 1^{+}$blood vessels within tumours per high-power field (Figure $3 \mathrm{C}$ and Supplementary Figure 2A). Previous studies demonstrated that a decrease in the number of blood vessels causes retardation of in vivo tumour growth as shown in Figure 3C from results of the present study (Hashizume et al, 2010; Yang et al, 2011; Kumar et al, 2012). Thus, ERO1- $\alpha$ expression in cancer cells facilitated tumour angiogenesis
A

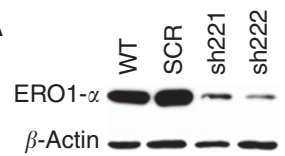

B

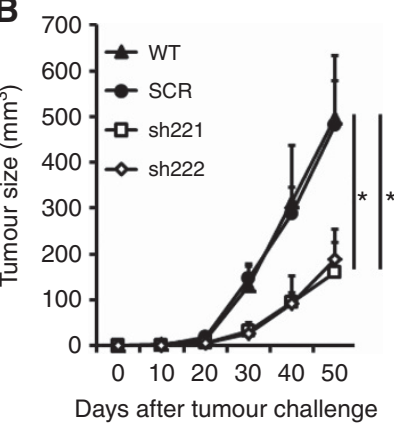

E

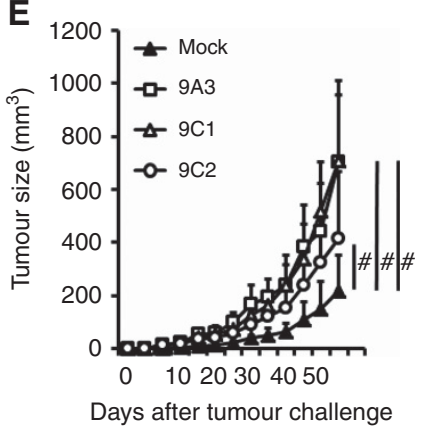

C

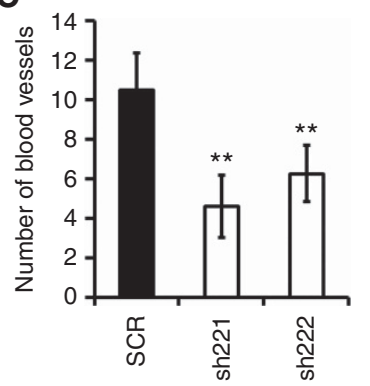

$\mathbf{F}$

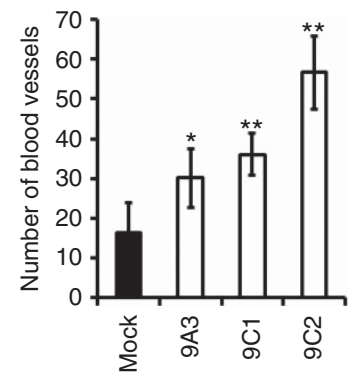

Figure 3. Expression of ERO1- $\alpha$ promoted tumour growth via augmenting angiogenesis. (A) Western blot analysis of MDA-MB-231 (wild-type (WT)) cells, scrambled shRNA-transfected (SCR) cells and ERO1- $\alpha$ knockdown (sh221 and sh222) cells. (B) Tumour growth rates of SCR, sh221 and sh222 cells were compared in NOD/SCID mice (five animals per group). (C) The numbers of blood vessels within SCR and $\mathrm{KD}$ cells per high-power field were compared. (D) Western blot analysis of mock cells and ERO1- $\alpha$-overexpressed (9A3, 9C1 and 9C2) cells.

(E) Tumour growth rates of mock, 9A3, 9C1 and 9C2 cells were compared in NOD/SCID mice (five animals per group). (F) The numbers of blood vessels within mock cells and OE cells per high-power field were compared. ${ }^{\#} P<0.001$, Mann-Whitney's $U$-test. ${ }^{*} P<0.01$, $\star \star P<0.001$, unpaired Student's t-test.

(neovascularization), thereby resulting in the promotion of tumour growth. To further examine the effect of ERO1- $\alpha$ on tumour growth and angiogenesis, we established ERO1- $\alpha$-overexpressed (9A3, 9C1 and 9C2) cell lines by introducing human cDNA of ERO1- $\alpha$ (Figure 3D). When NOD/SCID mice were challenged with mock cells and with 9A3, 9C1 and 9C2 cells, we observed that all of the $\mathrm{OE}$ tumours grew more aggressively than the mock tumour did (Figure $3 \mathrm{E}$ ). To investigate the mechanism by which the OE tumour grew more aggressively than the mock tumour did, the tumours were stained for CD31. Immunohistochemical analysis showed that overexpression of ERO1- $\alpha$ increased the number of $\mathrm{CD}_{3} 1^{+}$blood vessels per high-power field (Figure 3F and Supplementary Figure 2B). These results again suggested that the expression of ERO1- $\alpha$ promoted tumour angiogenesis.

Knockdown of ERO1- $\alpha$ inhibits secretion of VEGF by inhibition of oxidative protein folding. Overexpression of ERO1- $\alpha$ augments secretion of VEGF not only by promoting oxidative protein folding but also by increasing mRNA expression of VEGF. MDAMB-231 cells secreted a large amount of VEGF. To examine the effect of ERO1- $\alpha$ on secretion of VEGF, we measured the amounts 
A

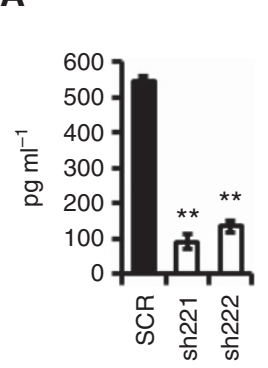

D

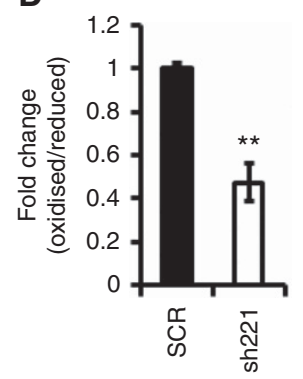

B

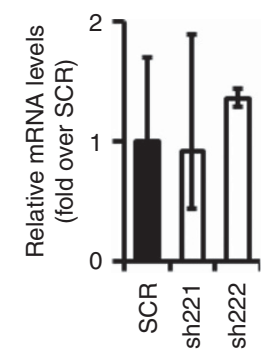

E

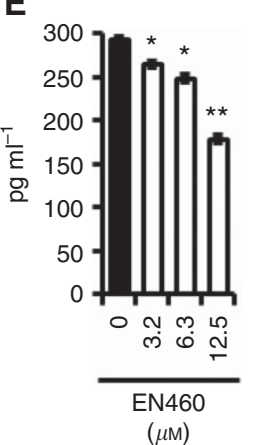

C

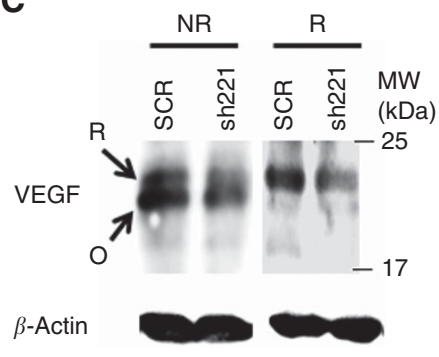

F

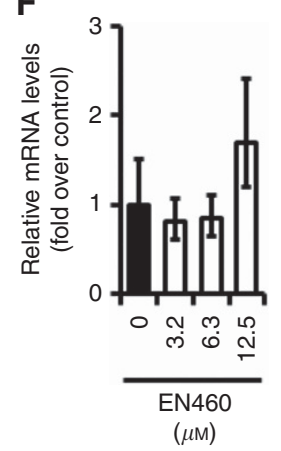

G

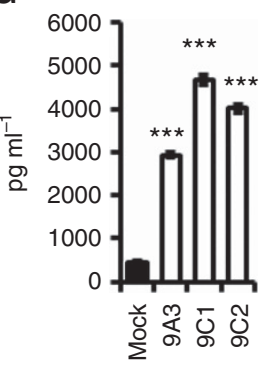

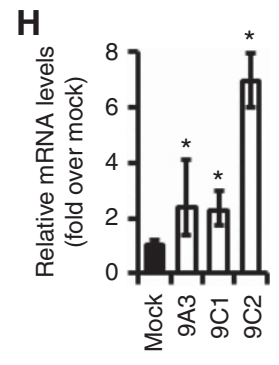

K

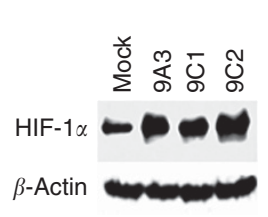

I
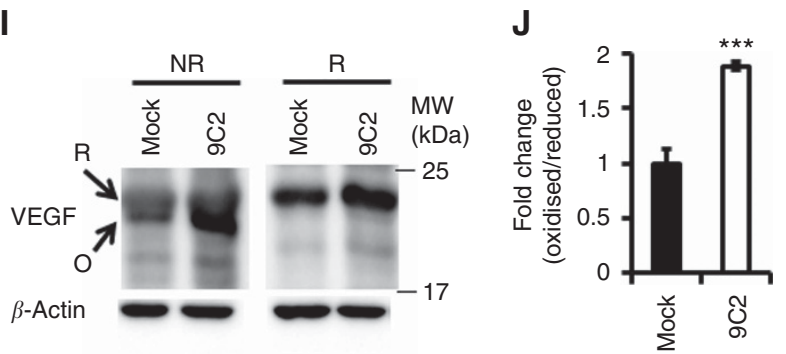

L
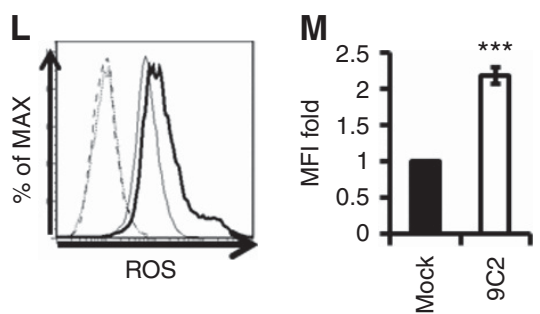

Figure 4. ERO1- $\alpha$ influenced the VEGF secretion via both promoting disulfide formation and the mRNA expression level. (A) Concentrations of VEGF in the 24-h culture supernatants from SCR, sh221 and sh222 cells were measured using ELISA. (B) VEGF mRNA expression levels in SCR, sh221 and sh222 cells were determined by real-time PCR analysis. (C, D) Redox status of VEGF in SCR and KD cells was examined by Western blotting under reducing (R) or non-reducing (NR) conditions. Reduced form (R) and oxidised form (O) of VEGF are indicated. The ratio of the oxidised form (O) and reduced form (R) obtained in SCR cells was set as 1 , and the differences in the ratio of the oxidised form (O) and reduced form (R) induced by sh221 cells were plotted. (E) Concentrations of VEGF in the 24-h culture supernatants from non-treated MDA-MB-231 cells and MDA-MB-231 cells treated with an ERO1- $\alpha$ inhibitor were measured using ELISA. (F) VEGF mRNA expression levels in non-treated MDA-MB-231 cells and MDA-MB-231 cells treated with an ERO1- $\alpha$ inhibitor were determined by real-time PCR analysis. (G) Concentrations of VEGF in the 24-h culture supernatants from mock, 9A3, 9C1 and 9C2 cells were measured using ELISA. (H) VEGF mRNA expression levels in mock, 9A3, 9C1 and 9C2 cells were determined by real-time PCR analysis. (I, J) Redox status of VEGF in mock and OE cells was examined by Western blotting under reducing (R) or non-reducing (NR) conditions. Reduced form (R) and oxidised form (O) of VEGF are indicated. The ratio of the oxidised form (O) and reduced form (R) obtained in mock cells was set as 1 , and the differences in the ratio of the oxidised form $(\mathrm{O})$ and reduced form $(\mathrm{R})$ induced by $9 \mathrm{C} 2$ cells were plotted. (K) Western blot analysis of mock, 9A3, 9C1 and 9C2 cells. (L, M) The amount of ROS in 9C2 (bold line) cells was compared with that in mock (thin line) cells. Dotted line and dashed line show unstained cells. The mean fluorescence intensity (MFI) value obtained in mock cells was set as 1 ,

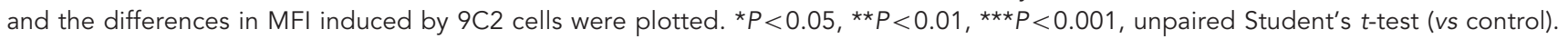

of VEGF produced by SCR and KD cells using ELISA. We observed that SCR cells produced a larger amount of VEGF than the KD cells (Figure 4A). Previous studies demonstrated that the number of blood vessels was decreased by a reduction in the amount of VEGF production as shown in Figure 4A from results of the present study (Hashizume et al, 2010; Yang et al, 2011; Kumar 
A

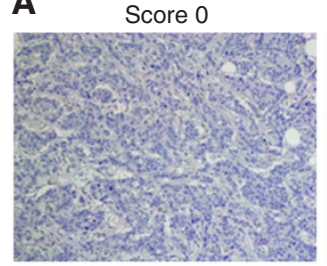

Score $2+$

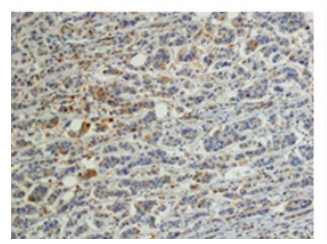

B

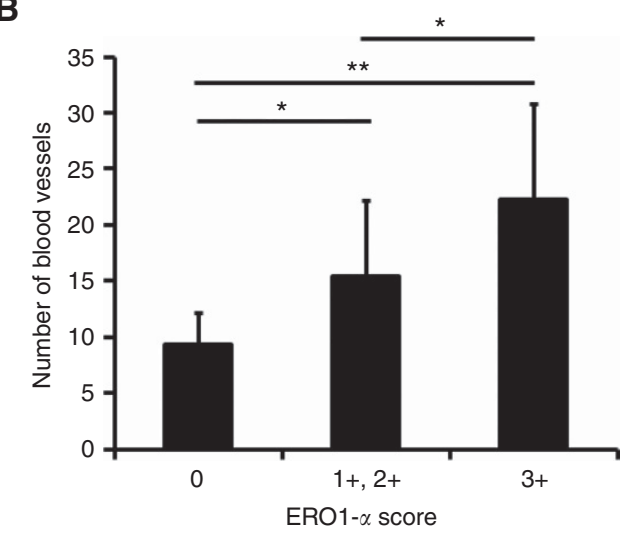

Figure 5. Expression of ERO1- $\alpha$ in TNBC was involved in angiogenesis in clinical cases. (A) TNBCs were classified into four groups by stainability for ERO1- $\alpha$. (B) The correlations of TNBCs with expression of ERO1- $\alpha$ and numbers of blood vessels were examined. The $P$-values are given for differences in median values. ${ }^{\star} P<0.05,{ }^{\star \star} P<0.001$, Tukey's test.

et al, 2012). To confirm these findings, we examined the effect of ERO1- $\alpha$ knockdown using various types of cancer cell lines (breast cancer cell lines MDA-MB-157 and MCF7, pancreatic cancer cell line MIAPaCa2 and gastric cancer cell line MKN45). We further found that control cells produced a larger amount of VEGF than the ERO1- $\alpha$ knockdown cells by using MCF7, MDA-MB-157, MIAPaCa2 and MKN45 cells (Supplementary Figure 3A-H). To determine the effect of ERO1- $\alpha$ on VEGF mRNA expression level, we compared VEGF mRNA expression levels by real-time RTPCR. VEGA mRNA expression levels were not different in SCR cells and $\mathrm{KD}$ cells (Figure 4B). In addition, VEGA mRNA expression levels were not different in control cells and ERO1- $\alpha$ knockdown cells when we used MCF7, MDA-MB-157, MIAPaCa2 and MKN45 cells (Supplementary Figure 3I-L). As ERO1- $\alpha$ is known to act as an oxidoreductase, we investigated the redox states of VEGF in SCR cells and KD cells by Western blot analysis under a non-reducing condition using MMTS. We found that the ratio of the oxidised form (mature form) to the reduced form (immature form) of VEGF in KD cells was lower than that in SCR cells under a non-reducing condition (Figure 4C and D). Moreover, we found that the total amount of VEGF protein in KD cells decreased under a reducing condition compared with the total amount in SCR cells. We speculated that the reduction in the total amount of VEGF protein in $\mathrm{KD}$ cells depended on degradation via ER-associated degradation. This will be examined in the future. To further examine the effect of ERO1- $\alpha$ on production of VEGF, we treated
MDA-MB-231 cells with the ERO1- $\alpha$ inhibitor EN460. When we compared non-treated MDA-MB-231 cells with MDA-MB-231 cells that had been treated with EN460, we observed that the nontreated MDA-MB-231 cells produced a larger amount of VEGF than the treated MDA-MB-231 cells (Figure 4E). However, EN460 treatment did not affect the mRNA levels of VEGF (Figure 4F). It has been shown that VEGF has inter- and intra-molecular disulfide bonds (Mandal and Kent, 2011) and that disulfide bond formation is required for VEGF to exert its biological activity. Taking this into account, these results indicated that tumour ERO1- $\alpha$ has a pivotal role in the generation of disulfide bonds within VEGF at the post-transcriptional level. On the other hand, when we examined the amounts of VEGF secreted by mock cells and all of the OE cells, we found that the amounts of VEGF secreted by all of OE cells was larger than that secreted by the mock cells (Figure $4 \mathrm{G}$ ). As ERO1- $\alpha$ is known to act as an oxidoreductase, we investigated the redox states of VEGF in mock cells and OE cells by Western blot analysis under a nonreducing condition using MMTS. We found that the ratio of the oxidised form (mature form) to the reduced form (immature form) of VEGF in OE cells was higher than that in mock cells under a non-reducing condition (Figure $4 \mathrm{I}$ and J). Next, when we examined the effect of ERO1- $\alpha$ on VEGF mRNA expression levels, we found that the VEGF mRNA level in all of the OE cells was significantly higher than that in mock cells (Figure $4 \mathrm{H}$ ). Because the VEGF mRNA expression level was enhanced by hypoxia-inducible factor $1 \alpha$ (HIF-1 $\alpha$ ) (Supplementary Figure 4), we compared the expression levels of HIF- $1 \alpha$ protein in mock cells and all of the OE cells. We found that the expression of HIF- $1 \alpha$ protein in OE cells was enhanced (Figure $4 \mathrm{~K}$ ). It is wellknown that HIF- $1 \alpha$ protein is accumulated by reactive oxygen species (ROS). Therefore, we examined the ROS levels in mock cells and OE cells. We found that ROS levels in OE cells were significantly increased compared with those in mock cells (Figure $4 \mathrm{~L}$ and $\mathrm{M}$ ). These results suggested that ERO1- $\alpha$ influenced not only protein oxidative folding of VEGF but also VEGF mRNA expression via accumulation of HIF- $1 \alpha$ by ROS which ERO1- $\alpha$ produced.

Expression of ERO1- $\alpha$ correlates with angiogenesis in clinical cases. TNBCs were stained for ERO1- $\alpha$ and were categorised into 4 groups (scores of $0-3+$; Figure $5 \mathrm{~A}$ ). Immunohistochemical staining for CD31 showed that differences in the numbers of CD $31^{+}$blood vessels in ERO1- $\alpha$ score 0 , score $1+, 2+$ and score $3+$ tumours (Supplementary Figure 5). Quantification analysis showed that the expression of ERO1- $\alpha$ correlated with the number of blood vessels (Figure 5B).

\section{DISCUSSION}

Most of the proteins that are secreted by cells or expressed on the cell-surface have intra- and/or inter-molecular disulfide bonds. These disulfide bonds are required for proper protein function. Thus, oxidative protein folding is critical for normal cell function and homoeostasis. Among the oxidoreductases expressed in the endoplasmic reticulum, ERO1- $\alpha$ is central to oxidative protein folding, but its expression varies in a tissue-specific manner (Kutomi et al, 2013). Furthermore, we previously showed that ERO1- $\alpha$ is overexpressed in various types of cancer cells and cancer tissues (Kutomi et al, 2013) and influences the formation of disulfide bonds of granulocyte colony-stimulating factor, CXC chemokine ligands 1 and 2 (Tanaka et al, 2015). It is known that the formation of a disulfide bond by ERO1- $\alpha$ is accompanied by the production of ROS such as hydrogen peroxide $\left(\mathrm{H}_{2} \mathrm{O}_{2}\right.$; Bell et al, 2007; Inaba et al, 2010). When we compared ROS levels in mock cells and OE cells, we found that ROS level in OE cells was 
higher than that in mock cells. Moreover, it has been shown that ROS induce stabilisation of HIF- $1 \alpha$ protein through inhibition of prolyl hydroxylase enzyme function (Bell et al, 2007; Kaelin and Ratcliffe, 2008; Blais et al, 2010; Inaba et al, 2010; Finley et al, 2011; Ma et al, 2013). As a result, HIF-1 $\alpha$ accompanied by HIF- $1 \alpha$ binds to hypoxic response elements of target genes (Loboda et al, 2005; Imtiyaz and Simon, 2010; Al-Mehdi et al, 2012; Ma et al, 2013). Our results suggested that ROS, which are products of ERO1- $\alpha$-mediated oxidative folding, upregulate the mRNA expression of VEGF via stabilisation of HIF- $1 \alpha$ protein.

VEGF is a covalent homodimeric protein with three intramolecular disulfides in each polypeptide chain and with two inter-chain disulfide bonds covalently joining the two identical monomers (Mandal and Kent, 2011). MDA-MB-231 tumour cells secreted a large amount of VEGF. In contrast, ERO1- $\alpha$ knockdown cells showed decreased secretion of VEGF. Therefore, we hypothesised that ERO1- $\alpha$ is also involved in the proper oxidative protein folding of VEGF before it is secreted, and that the loss of ERO1- $\alpha$ leads to decreased production of functionally active VEGF as shown by Western blotting under a non-reducing condition (Figure 4C). To further confirm that what we observed is a post-transcriptional event, we conducted real-time RT-PCR on SCR and KD cells. We did not observe differences in mRNA levels of VEGF among the three cell lines, suggesting that ERO1- $\alpha$ acted at the posttranslational level.

We showed that ERO1- $\alpha$ contributed to angiogenesis by augmentation of VEGF production at the protein level and mRNA level. We could not determine whether ERO1- $\alpha$ directly formed a mixed disulfide intermediate with VEGF or whether ERO1- $\alpha$ cooperated with protein disulfide isomerase to produce disulfide bonds within VEGF in the ER. These questions need to be clarified. Although further studies are needed to understand the role of ERO1- $\alpha$ in vivo, the results presented here strongly suggest that targeted inhibition of ERO1- $\alpha$ is a promising strategy for treatment of breast cancer.

\section{ACKNOWLEDGEMENTS}

This work was supported in part by a Grant-in-Aid for Scientific Research from The Ministry of Education, Culture, Sports, Science and Technology of Japan.

\section{CONFLICT OF INTEREST}

The authors declare no confict of interest.

\section{REFERENCES}

Al-Mehdi AB, Pastukh VM, Swiger BM, Reed DJ, Patel MR, Bardwell GC, Pastukh VV, Alexeyev MF, Gillespie MN (2012) Perinuclear mitochondrial clustering creates an oxidant-rich nuclear domain required for hypoxia-induced transcription. Sci Signal 5: ra47.

Bell EL, Klimova TA, Eisenbart J, Moraes CT, Murphy MP, Budinger GR, Chandel NS (2007) The Qo site of the mitochondrial complex III is required for the transduction of hypoxic signaling via reactive oxygen species production. J Cell Biol 177: 1029-1036.

Blais JD, Chin KT, Zito E, Zhang Y, Heldman N, Harding HP, Fass D, Thorpe C, Ron D (2010) A small molecule inhibitor of endoplasmic reticulum oxidation 1 (ERO1) with selectively reversible thiol reactivity. J Biol Chem 285: 20993-21003.

Curado MP (2011) Breast cancer in the world: incidence and mortality. Salud Publica Mex 53: 372-384.
Finley LW, Carracedo A, Lee J, Souza A, Egia A, Zhang J, Teruya-Feldstein J, Moreira PI, Cardoso SM, Clish CB, Pandolfi PP, Haigis MC (2011) SIRT3 opposes reprogramming of cancer cell metabolism through HIF $1 \alpha$ destabilization. Cancer Cell 19: 416-428.

Hashizume H, Falcón BL, Kuroda T, Baluk P, Coxon A, Yu D, Bready JV, Oliner JD, McDonald DM (2010) Complementary actions of inhibitors of angiopoietin-2 and VEGF on tumor angiogenesis and growth. Cancer Res 70: 2213-2223.

Hong L, Han Y, Zhou Y, Nita A (2013) Angiogenesis-related microRNAs in colon cancer. Expert Opin Biol Ther 13: 77-84.

Hua Z, Lv Q, Ye W, Wong CK, Cai G, Gu D, Ji Y, Zhao C, Wang J, Yang BB, Zhang Y (2006) MiRNA-directed regulation of VEGF and other angiogenic factors under hypoxia. PLoS One 1: el16.

Imtiyaz HZ, Simon MC (2010) Hypoxia-inducible factors as essential regulators of inflammation. Curr Top Microbiol Immunol 345: $105-120$.

Inaba K, Masui S, Iida H, Vavassori S, Sitia R, Suzuki M (2010) Crystal structures of human Erol $\alpha$ reveal the mechanisms of regulated and targeted oxidation of PDI. EMBO J 29: 3330-3343.

Kaelin Jr WG, Ratcliffe PJ (2008) Oxygen sensing by metazoans: the central role of the HIF hydroxylase pathway. Mol Cell 30: 393-402.

Kuehbacher A, Urbich C, Dimmeler S (2008) Targeting microRNA expression to regulate angiogenesis. Trends Pharmacol Sci 29: 12-15.

Kukita K, Tamura Y, Tanaka T, Kajiwara T, Kutomi G, Saito K, Okuya K, Takaya A, Kanaseki T, Tsukahara T, Hirohashi Y, Torigoe T, Furuhata T, Hirata K, Sato N (2015) Cancer-associated oxidase ERO1- $\alpha$ regulates the expression of MHC class I molecule via oxidative folding. J Immunol 194: 4988-4996.

Kumar B, Yadav A, Lang J, Teknos TN, Kumar P (2012) Dysregulation of microRNA-34a expression in head and neck squamous cell carcinoma promotes tumor growth and tumor angiogenesis. PLoS One 7: e37601.

Kutomi G, Tamura Y, Tanaka T, Kajiwara T, Kukita K, Ohmura T, Shima H, Takamaru T, Satomi F, Suzuki Y, Torigoe T, Sato N, Hirata K (2013) Human endoplasmic reticulum oxidoreductin $1-\alpha$ is a novel predictor for poor prognosis of breast cancer. Cancer Sci 104: 1091-1096.

Lee DY, Deng Z, Wang CH, Yang BB (2007) MicroRNA-378 promotes cell survival, tumor growth, and angiogenesis by targeting SuFu and Fus-1 expression. Proc Natl Acad Sci USA 104: 20350-20355.

Loboda A, Jazwa A, Wegiel B, Jozkowicz A, Dulak J (2005) Heme oxygenase-1-dependent and -independent regulation of angiogenic genes expression: effect of cobalt protoporphyrin and cobalt chloride on VEGF and IL-8 synthesis in human microvascular endothelial cells. Cell Mol Biol 51: 347-355.

Ma J, Zhang Q, Chen S, Fang B, Yang Q, Chen C, Miele L, Sarkar FH, Xia J, Wang Z (2013) Mitochondrial dysfunction promotes breast cancer cell migration and invasion through HIF $1 \alpha$ accumulation via increased production of reactive oxygen species. PLoS One 8: e69485.

Mandal K, Kent SB (2011) Total chemical synthesis of biologically active vascular endothelial growth factor. Angew Chem Int Ed Engl 50: 8029-8033.

Mittendorf EA, Philips AV, Meric-Bernstam F, Qiao N, Wu Y, Harrington S, Su X, Wang Y, Gonzalez-Angulo AM, Akcakanat A, Chawla A, Curran M, Hwu P, Sharma P, Litton JK, Molldrem JJ, Alatrash G (2014) PD-L1 expression in triple-negative breast cancer. Cancer Immunol Res 2: 361-370.

Redondo A, Martínez V, Zamora P, Castelo B, Pinto A, Cruz P, Higuera O, Mendiola M, Hardisson D, Espinosa E (2014) Continuation of bevacizumab and addition of hormone therapy following weekly paclitaxel therapy in HER2-negative metastatic breast cancer. Onco Targets Ther 7: 2175-2181.

Tanaka T, Kajiwara T, Torigoe T, Okamoto Y, Sato N, Tamura Y (2015) Cancer-associated oxidoreductase ERO1- $\alpha$ drives the production of tumor-promoting myeloid-derived suppressor cells via oxidative protein folding. J Immunol 194: 2004-2010.

Wang S, Olson EN (2009) AngiomiRs-key regulators of angiogenesis. Curr Opin Genet Dev 19: 205-211.

Xu WW, Li B, Lam AK, Tsao SW, Law SY, Chan KW, Yuan QJ, Cheung AL (2015) Targeting VEGFR1- and VEGFR2-expressing non-tumor cells is essential for esophageal cancer therapy. Oncotarget 6 : 1790-1805. 
Yang L, Chen G, Mohanty S, Scott G, Fazal F, Rahman A, Begum S, Hynes RO, $\mathrm{Xu}$ L (2011) GPR56 Regulates VEGF production and angiogenesis during melanoma progression. Cancer Res 71: 5558-5568.

Zhang X, Tang J, Zhi X, Xie K, Wang W, Li Z, Zhu Y, Yang L, Xu H, Xu Z (2015) miR-874 functions as a tumor suppressor by inhibiting angiogenesis through STAT3/VEGF-A pathway in gastric cancer. Oncotarget 6: 1605-1617.

Zhu LM, Shi DM, Dai Q, Cheng XJ, Yao WY, Sun PH, Ding Y, Qiao MM, Wu YL, Jiang SH, Tu SP (2014) Tumor suppressor XAF1 induces apoptosis, inhibits angiogenesis and inhibits tumor growth in hepatocellular carcinoma. Oncotarget 5: 5403-5415.

This work is published under the standard license to publish agreement. After 12 months the work will become freely available and the license terms will switch to a Creative Commons AttributionNonCommercial-Share Alike 4.0 Unported License.

Supplementary Information accompanies this paper on British Journal of Cancer website (http://www.nature.com/bjc) 